\author{
Heike Alps
}

\title{
Beilegung individualarbeitsrechtlicher Streitigkeiten in Japan
}

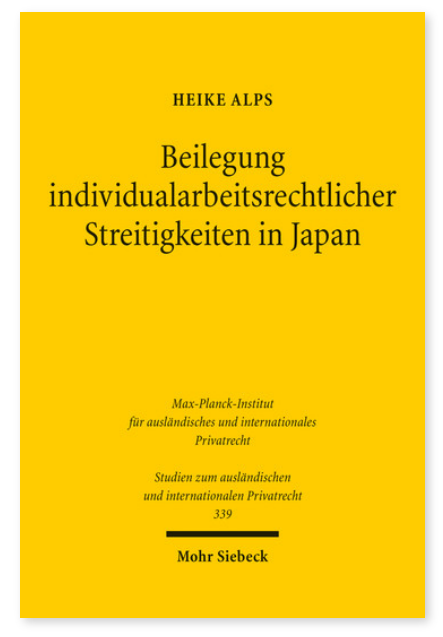

2015. XXIII, 352 Seiten. StudIPR 339

ISBN 978-3-16-153403-4

DOI 10.1628/978-3-16-153403-4

eBook PDF 89,00€

ISBN 978-3-16-153365-5

fadengeheftete Broschur $89,00 €$
Individualarbeitsrechtliche Streitigkeiten sind in Japan über einen langen Zeitraum hinweg nicht als bedeutsamer Konflikttypus wahrgenommen worden. Erst zu Beginn des neuen Jahrtausends wurden zwei Systeme eingeführt, die landesweit für ganz Japan einheitliche Regelungen speziell nur für die Beilegung individualarbeitsrechtlicher Konflikte vorsehen. Im Jahr 2001 ist ein Vermittlungsverfahren auf Verwaltungsebene und im Jahr 2006 das Verfahren über die Verständigung in Arbeitssachen vor den japanischen Distriktgerichten eingeführt worden. Japan gilt als Land, in dem Konflikte überwiegend mit Hilfe von Verfahren gelöst werden, deren Ziel die einvernehmliche Beilegung eines Streites ist. Das Verständigungsverfahren weist viele Gemeinsamkeiten mit solch alternativen Streitbeilegungsverfahren auf. Die Analyse und rechtliche Einordnung der beiden neu etablierten Verfahren ist das Ziel dieses Beitrags.

Heike Alps Geboren 1976; Studium der Rechtswissenschaften in Trier und Tübingen; Postgraduiertenstudium »apanische Sprache und Kultur « an der Universität Tübingen und der Dōshisha Universität in Kyoto, Japan; Studienaufenthalt in Kyoto; Referendariat in Lübeck und Hamburg; Masterstudiengang Recht an der Chūō Universität in Tokyo, Japan; seit 2005 Tätigkeit als Rechtsanwältin; seit 2012 Lehrauftrag für »Einführung in die japanische Rechtssprache« an der Universität Augsburg; 2013 Promotion, Marburg.

Jetzt bestellen:

https://mohrsiebeck.com/buch/beilegung-individualarbeitsrechtlicher-streitigkeiten-in-japan-9783161534034?no_cache=1 order@mohrsiebeck.com

Telefon: +49 (0)7071-923-17

Telefax: +49(0)7071-51104 